\title{
ОБЩИЕ ТЕНДЕНЦИИ УСТОЙЧИВОГО РАЗВИТИЯ АЗЕРБАЙДЖАНСКОЙ РЕСПУБЛИКИ В КОНТЕКСТЕ ЦЕЛИ РАЗВИТИЯ ТЫСЯЧЕЛЕТИЯ
}

\author{
УЛЬфат МЕХДИЕВ \\ Академии Государственного Управления при Президенте \\ Азербайджанской РеспубликиАзербайджан , Баку, Азербайджан
}

\section{1. Введение}

На исходе XX столетия необычайно обострилась борьба за ресурсы, глобальные изменения окружающей среды, влияющие на экономику и здоровье людей, произошло небывалое расслоение мира по доходам, существенно увеличившее масштабы бедности. В результате возникла проблема беспрецедентной сложности - необходимость формирования, по существу, новой модели развития цивилизации, которая могла бы противостоять надвигающемуся глобальному социально-политическому, экономическому и экологическому кризису. Соответственно, все это требует принципиально новый подход также к проблеме человеческого развития. В Азербайджанской Республике разрабатываются эффективные концептуальные основы для формирования и развития человеческого потенциала. Так как, новые тренды развития национальной экономической системы дают импульс развитию также человеческого капитала. В представленной научной статье в основном рассматриваются общие тенденции развития человеческого потенциала в Азербайджанской Республике контексте концепции Цели Развития Тысячелетия. 


\section{Цели Развития Тысячелетия и Азербайджан}

Прежде всего, отметим, что ЦРТ получили официальное признание и широкое распространение в мире и отдельных странах, послужив новым стимулом к действиям по борьбе с бедностью. ЦРТ стали признанием того, что их приоритетность следует определять в контексте национальных стратегий развития и, что традиционный взгляд на развитие человеческого потенциала нуждается в систематизации. Человечество добилось существенных успехов в реализации ЦРТ, прогресс наблюдался по всем целям и задачам, что отразили соответствующие индикаторы мониторинга. Во всем мире число людей, живущих в условиях крайней нищеты, сократилось более чем наполовину, уменьшившись с 1,9 млрд чел. в 1990 году до 836 млн чел. в 2015 году. С 2000 года расширилась сфера образования, прежде всего в развивающихся странах. Коэффициент охвата начальным образованием в развивающихся регионах в 2015 году достиг $91 \%$ по сравнению с $83 \%$ в 2000 году. Доля грамотных среди молодежи в возрасте от 15 до 24 лет за период 1990-2015 годов во всем мире увеличилась на столько же. Значительны достижения человечества в сфере здоровья, особенно среди детей и матерей и т. д.

На тот период борьба с бедностью была приоритетным направлением национальной политики государства, поэтому Правительство Азербайджана определило, что достигнуть глобальные ЦРТ возможно в рамках стратегии сокращения бедности в стране. С этой целью была принята Государственная программа по сокращению бедности и экономическому развитию в Азербайджанской Республике (ГПСБЭР) на 2003-2005 годы. ГПСБЭР наметила шесть ключевых стратегических задач для достижения общих целей сокращения бедности и экономического развития, а именно:

1. Создание благоприятных условий для роста возможностей получения дохода.

2. Поддержание макроэкономической стабильности.

3. Улучшение качества и справедливости доступа к базовым услугам здравоохранения и образования.

4. Улучшение инфраструктуры (включая дороги, оказание коммунальных услуг, связь, ирригащия и д.р.).

5. Реформа существующей системь социальной защиты для обеспечения более эффективной защиты уязвимых групп населения.

6. Улучшение условий жизни и возможностей беженцев и вынужденных переселенцев. 
ГПСБЭР охватывала следующие приоритетные направления:

-экономическое развитие и увеличение занятости;

- социальная политика и развитие человеческого потенцииала;

- региональная политика и развитие инфраструктуры;

- институциональные реформы и наращивание потенциала ( 2)

Совершенно очевидно, что ЦРТ и ГПСБЭР имеют общую цель - сокращение бедности, при этом стратегические задачи и приоритетные направления, обозначенные в ГПСБЭР, во многом созвучные идеологии ЦРТ, стали основой для полной интеграции и достижения ЦРТ.(6)

Адаптация ЦРТ проводилась в тесном сотрудничестве с представительствами ПРООН, ВБ и МВФ в Азербайджане, путем консультаций с заинтересованными государственными структурами, научноисследовательскими учреждениями и гражданским обществом. Проекты политических предложений, выдвигаемых в стратегическом документе, обсуждались на различных национальных и региональных семинарах. В результате, было сохранено базовое количество Целей, при этом некоторые из них, при сохранении концептуального подхода глобальных ЦРТ были переформулированы с учетом местных реалий и специфики. Министерство Экономики Азербайджанской Республики выполняло координирующую функцию, а также осуществляло мониторинг по достижению ЦРТ. (9).

В достижении ЦРТ и регулировании политики в сфере сокращение бедности важную роль сыграли законы Азербайджанской Республики «О прожиточном минимуме», «О социальных пособиях», «О трудовых пенсиях», «О занятости населения», принятые в период после 2000 года.

В 2008 году была принята вторая Государственная Программа "Сокращение бедности и устойчивое развитие в Азербайджанской Республике в 2008-2015 годах" (ГПСБУР), в которую были полностью интегрированы адаптированные для страны ЦРТ. Стратегические цели ГПСБУР являлись логическим продолжением ГПСБЭР при соблюдении принципов полной методологической преемственности.

Следует отметить, что на процесс достижения ЦРТ существенное влияние оказало состояние макроэкономической ситуации в стране, которая значительно укрепилась в течение 2000-2014 годов. Так, национальный ВВП увеличился примерно в 12,5 раза и составил 58,98 миллиардов манат, при этом ненефтяной ВВП увеличился в 11,7 раза и составил более 33,0 миллиарда манатов. (Рис 2.2.3). 


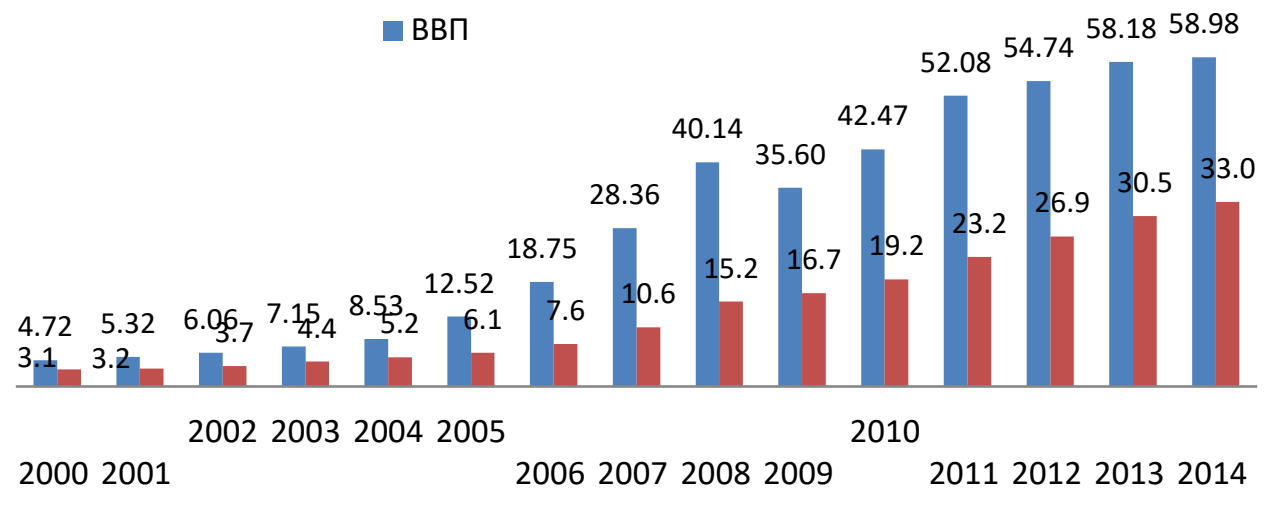

Рисунок 2.2.3 Динамика роста ВВП и ненефтяного ВВП в Азербайджанской Республике за 2001-2014 гг.(млрд. АЗН). Источник: [1]

Более чем в 19,4 раза увеличился объем инвестиций в страну и составил 193,0 миллиардов долларов США, из которых 53,0\% - местные инвестиции (Таблица 2.2.1).

Таблица 2.2.1. Инвестиции направленные в экономику с 2000 по 2014 гг.

\begin{tabular}{|l|l|l|l|l|l|l|}
\hline \multirow{2}{*}{$\begin{array}{l}\text { Период } \\
\text { времени }\end{array}$} & \multicolumn{2}{|l|}{$\begin{array}{l}\text { Общая сумма } \\
\text { инвестиций }\end{array}$} & \multicolumn{2}{|l|}{$\begin{array}{l}\text { Внутренние } \\
\text { инвестиции }\end{array}$} & \multicolumn{2}{l|}{$\begin{array}{l}\text { Зарубежные } \\
\text { инвестиции }\end{array}$} \\
\cline { 2 - 7 } & млн. USD & $\%$ & \multicolumn{2}{|l|}{$\begin{array}{l}\text { млн. } \\
\text { USD }\end{array}$} & $\%$ & \multicolumn{2}{l|}{$\begin{array}{l}\text { млн. } \\
\text { USD }\end{array}$} & $\%$ \\
\hline 2000 & 1441.4 & 100 & 514.4 & 35.7 & 927 & 64.3 \\
\hline 2005 & 7118.5 & 100 & 2225.3 & 31.3 & 4893.2 & 68.7 \\
\hline 2010 & 17591.4 & 100 & 9343.6 & 53.1 & 8247.8 & 46.9 \\
\hline 2014 & 27907.5 & 100 & 16209.8 & 58.1 & 11697.7 & 41.9 \\
\hline $2000-2014$ & 192995.0 & 100 & 102384.2 & 53.1 & 90610.8 & 46.9 \\
\hline
\end{tabular}

Источник: [7 ].

Как видно из таблицы 2.2.1, за 2000-2014 годы внутренние инвестиции увеличились в 31,5 раза и их доля в общем объеме инвестиций, направленных на развитие национальной экономики, увеличилась с 35,7\% до 58,1\%.

Динамичное развитие макроэкономики способствовало снижению безработицы, сохранению низкого уровня инфляции, а также повышению в несколько раз минимальных социальных стандартов и доходов населения.

Анализ и оценка достижений ЦРТ в стране были представлены в двух национальных отчета (2005 г., 2015 г.), подготовленных при поддержке ПРООН. Проведя анализ программных документов и, опираясь на данные национальных отчетов, прогресс в достижение ЦРТ в Азербайджане заключался в следующем: 
Учитывая специфику развития страны, в качестве основных приоритетов были выбраны ликвидация крайней бедности и сокращение низких доходов населения. Уровень бедности определялся по установленному прожиточному минимуму. По определению бедным считается человек, имеющий доход ниже прожиточного минимума.

В целевую задачу входило снижение уровня бедности вдвое, и эта задача была выполнена досрочно, к концу 2006 года. Уровень абсолютной бедности в стране снизился с 49,0\% в 2001 году до 4,9\% в 2015 году, при этом крайняя бедность была снижена до невероятного уровня $(<0,1)$.

Сокращению бедности во многом способствовало увеличение занятости. В течение 2004-2014 годов в стране было создано 1365000 новых рабочих мест, что привело к снижению безработицы. (Рис.2.2.4)

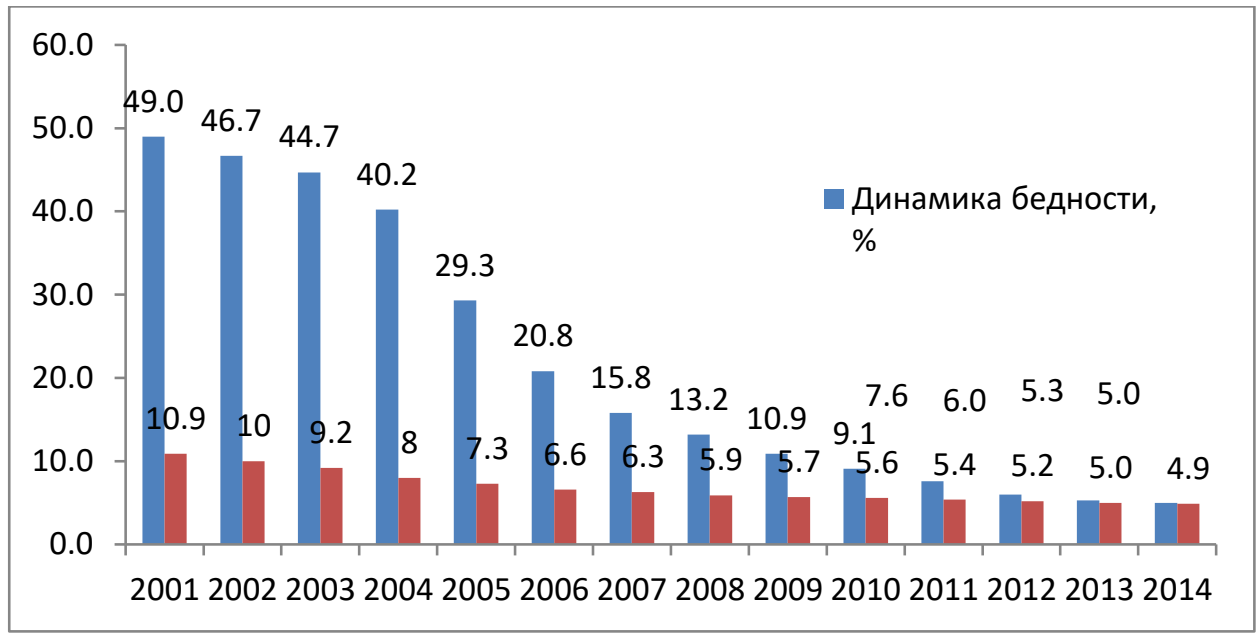

Рисунок 2.2.4 Динамика уровня бедности и безработицы в Азербайджанской Республике за 2001-2015 гг.(\%) .Источник: [1]

Как видно, из рисунка 2.2.4 уровень безработицы с 10,9\% в 2001 году снизился до 4,9\% в 2014 году. Следует отметить, что снижение уровня бедности сопровождалось повышением минимального прожиточного уровня более чем в 5 раз. Средняя заработанная плата в период с 2000 по 2014 гг. увеличилась в 10 раз. (Рис.2.2.5) 


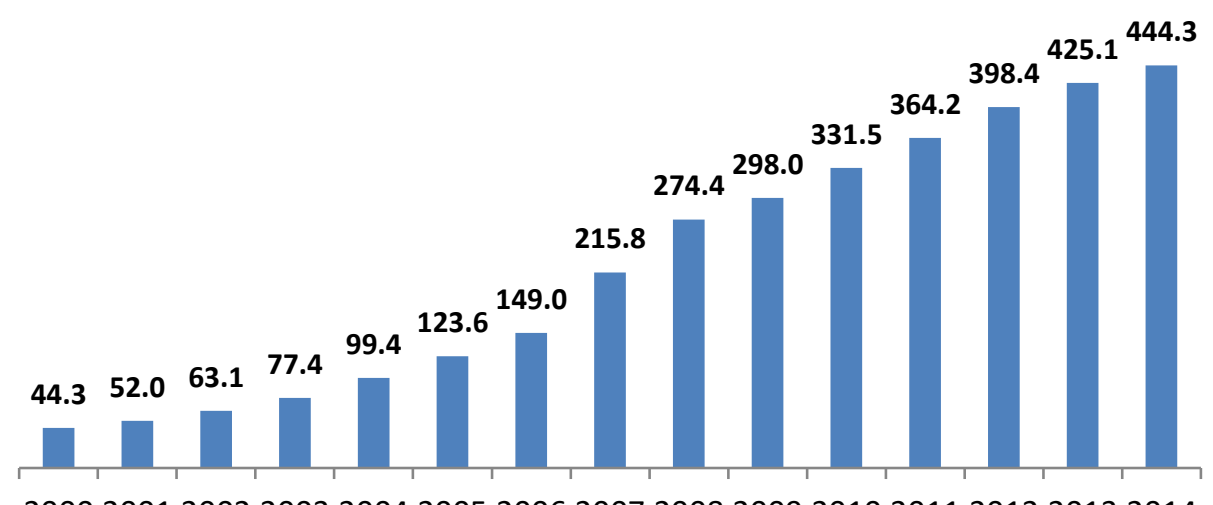

200020012002200320042005200620072008200920102011201220132014

Рисунок 2.2.5 Рост средней заработанной платы в Азербайджанской Республике за 2001-2014 гг.(АЗН). Источник: [1]

Улучшение социально-экономического положения позволило в течение 2001-2015 годов снизить число детей с недостаточным весом в возрасте до 5 лет с $6,8 \%$ до $0,6 \%$. Доля беднейшего квинтиля в национальном потреблении увеличилась по сравнению с базовым уровнем (13,2\% в 2002 году) и составила $15,5 \%$ в 2014 году. (9)

Являясь Целью развития тысячелетия, само по себе гендерное равенство это ключ к достижению всех ЦРТ. Признавая это, в 2005 году в Цели 1 и 5 был включен гендерный аспект, который дополнил их задачами по обеспечению полной, продуктивной и достойной занятости, особенно для женщин и молодежи, и всеобщему доступу к репродуктивному здоровью. Включение гендерного аспекта является обязательным требованием для всех ЦРТ. (5)

В Азербайджане был отмечен определенный прогресс в гендерном равноправии. Так, достигнуто гендерное равенство в системе среднего и высшего образовании, при этом доля грамотных женщин в возрасте от 15 до 24 лет составила 100\%. Среди лиц женского пола учащиеся средних школ составляли $67,4 \%$, ВУЗов - 48,5\%, аспирантуры - 52,5\%, докторантуры $48,0 \%$. Значительно увеличился индекс гендерного равенства во всех ступенях образования.

Реализация национальных ЦРТ и государственных программ по охране материнства и детства повысила обслуживание беременных женщин и младенцев во внутриутробном и послеродовом периодах, что позволило сократить материнскую смертность более чем в два раза. (Рис.2.2.8) 


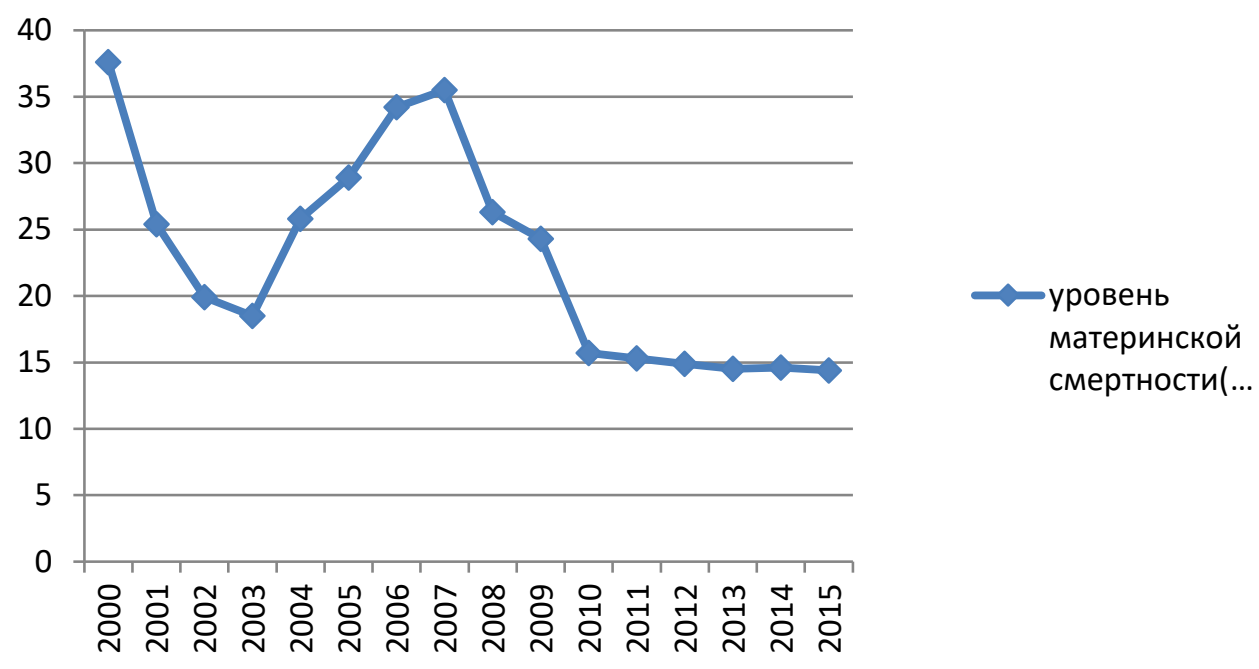

Рисунок 2.2.8 Динамика материнской смертности (на 100000 живорожденных).Источник: [1]

Как видно из рисунка 2.2.8, коэффициент материнской смертности на 100000 живорождений снизился с 37,6 в 2007 году до 14,4 в 2015 году. Кроме того, возросла доля родов с участием квалифицированного медицинского персонала с 92,1\% в 2000 году до 99.8 \% в 2015 году, что также повлияло на сокращение материнской смертности.

Обеспечение экологической устойчивости является также важной целю. Стратегической целью экологической политики в Азербайджанской Республике является эффективное использование природных ресурсов для обеспечения растущих потребностей нынешнего и будущих поколений. После приобретения независимости, было принято три экологических кодекса и более 40 законов по окружающей среде, страна присоединилась к более 20 -ти международным конвенциям и соглашениям.

Одним из важных индикаторов, характеризующих экологическую устойчивость страны, служит динамика изменения площадей охраняемых природных территорий. К ним относятся заповедники, национальные парки, заказники и другие категории земель, охраняемых с целью сохранения природных комплексов и биоразнообразия. (Алакбаров,2017, с.141-142).

В результате принятых мер площадь особо охраняемых природных земель за 2000-2014 годы увеличилась более чем в 2 раза и составляет 10,3\% от общей площади страны, в том числе с национальными парками - 3,7\%. (Рис.2.2.9) 


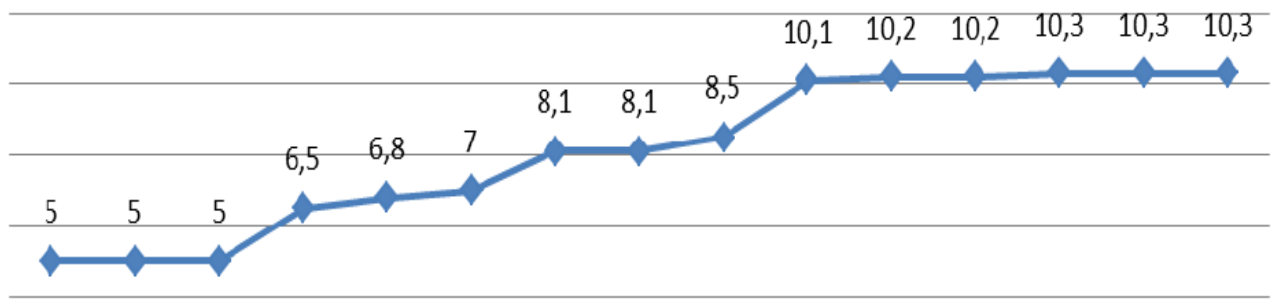

$2000 \quad 20012002 \quad 20032004200520062007200820092010 \quad 20112012 \quad 20132014$

Рисунок 2.2.9. Площадь особо охраняемых природных территорий (\%) Источник: [1]

Особо охраняемые природные территории составили 893 тыс. га, в том числе 9 национальных парков, 11 государственных заповедников и 24 государственных заповедника. (8).

Развитие глобального сотрудничества с целью прогресса определено как стратегическая задача перед государством. В 2000-2014 годах Азербайджанская Республика достигла значительных успехов по всем направлениям развития международного сотрудничества, включая донорскую миссию и внесла свой вклад в глобальное партнерство в целях развития. При этом, Азербайджан из страны-получателя помощи становится страной-донором, оказав помощь более 40 странам Африки, Азии и Латинской Америки.

Созданное при Министерстве иностранных дел в 2011 году Азербайджанское Агентство Международного Развития - AIDA, на основе двустороннего и многостороннего сотрудничества, поддерживает программы и проекты в развивающихся странах мира по сокращению бедности, развитию науки и культуры, здравоохранения, ИКТ, эффективному использование энергетических ресурсов и в других областях.

\section{Уровень реализации ЦРТ в Азербайджане}

Оценивая уровень достижения ЦРТ в Азербайджанской Республике, важно отметить, что адаптированная система показателей ни в коей мере не является устоявшейся и полной системой оценки. Вышеперечисленные индикаторы были взяты за основу, с тем, чтобы отслеживать позитивные тенденции достижения задач ЦРТ и направлять процесс развития страны с учетом национальных приоритетов. 
Таким образом, анализ целевых показателей мониторинга убедительно показал, что Азербайджанской Республике удалось добиться заметного прогресса в достижении ЦРТ. Реализация с учетом национальных ЦРТ ГПСБЭР и ГПСБУР, а также, государственных программ по социальноэкономическому развитию обусловили выполнение ключевых задач по достижению ЦРТ в стране к концу 2015 года.

Страна достигла впечатляющих успехов в сокращении масштабов бедности, обеспечении всеобщего образования, сокращении материнской и младенческой смертности, укреплении борьбы с опасными инфекционными и другими заболеваниями и обеспечении экологической устойчивости. Кроме того, Азербайджанская Республика успешно показала свою растущую роль в укреплении международного сотрудничества, уделяя особое внимание донорской поддержке развивающимся странам.

Азербайджан продемонстрировал политическую волю к достижению ЦРТ и решимость улучшить государственное управление, что четко прослеживается на этапах разработки и реализации ГПСБЭР и ГПСБУР. (7)

Заслуживает внимания тот факт, что стратегия сокращения бедности, разработана не какой-либо отдельной донорской организацией, a правительством Азербайджана и по оценке МВФ является успешным примером всестороннего сотрудничества и координации между различными государственными, международными организациями и гражданским обществом в разработке и реализации единой национальной стратегии. (6)

За достижения в реализации ЦРТ в 2015 году Президент Азербайджанской Республики Ильхам Алиев был удостоен международной премии «Юг-Юг»

Отдавая должное достигнутому прогрессу, необходимо отметить ряд вопросов, требующих дальнейшего развития, в частности:

- Достижение ЦРТ 1 произошло за счет снижения бедности по доходам или крайней бедности, тем не менее, необходимо пересмотреть критерии оценки бедности, а именно черту бедности целесообразно определять на уровне полной стоимости существующей потребительской корзины, как это принято в странах с устойчиво развивающейся экономикой.

- З Задача ЦРТ 8 по обеспечению молодежи достойной и продуктивной работой сталкивается серьезными противоречиями, возникающими между качеством образования и отсутствия соответствия потребностям рынка. Рынок требует опытных работников, и выпускники средних и высших учебных заведений остаются в этом контексте вне поля зрения работодателя. 
- Цель 7 по обеспечению экологической устойчивости является наиболее сложной для реализации из-за множества факторов, в числе которых существующие тенденции экономического развития республики, связанные с наращиванием объемов добычи и экспорта топливных запасов, что сопровождается утратой природных ресурсов и высоким уровнем техногенных загрязнений. Современный период развития можно охарактеризовать через три «Э»: энергетика, экономика, экология. Энергетика в этом ряду занимает особое место. От нее в решающей мере зависит экономический потенциал государства и благосостояние людей. Она же оказывает наиболее сильное воздействие на окружающую среду, экосистемы и биосферу в целом ( Розенберг , 2014). Проявившие себя за последние десятилетия острые экологические проблемы (изменение климата, разрушение озонового слоя, кислотные осадки и другие) прямо или косвенно связаны с производством либо с использованием энергии. В связи с этим необходим экосистемный подход сбалансированного и гармоничного использования ресурсов, при котором разные элементы управления были бы ориентированы на общий результат достижения экологической устойчивости.

- Анализ показателей, оценивающий достижения ЦРТ в области гендерного равенства, свидетельствует о том, что на уровне законодательства никакой дискриминации по полу не существует, однако на практике зачастую сохраняется разрыв между юридическим и фактическим равноправием. Многие женщины не могут в полной мере реализовать свой высокий образовательный потенциал в полной мере в связи с необходимостью совмещать профессиональные и семейные обязанности. Кроме того, необходимы более конкретные меры по снижению домашнего насилия, а для этого необходимо совершенствование нормативно-правовой базы, усиление работы правоохранительных структур, своевременные профилактические меры.

- Реализация ЦРТ выявила потребность в новых индикаторах, оценивающих качественные показатели образования, медицинских услуг и их доступности, которые имеют первостепенное значение в развитии человеческого потенциала. Также, требует усовершенствования методологии сбора и обработки данных.

Накопленный опыт в процессе реализации ЦРТ показал что, данные цели стали не только частью структурной и долгосрочной концепции развития Азербайджанской Республики, но и надежным ориентиром при разработке стратегий устойчивого развития и при формировании связанного с этим процессом политического курса. 


\section{Заключение}

Для достижения устойчивого прогресса в реализации глобальных ЦРТ, крайне важно было включить их в национальные программы развития, разработать экономически эффективные стратегии, отвечающие условиям развития страны, создать стимулирующую международное сотрудничество среду, а также разработать систему мониторинга с точными показателями для внесения изменений в данные стратегии с учетом их реального воздействия. В этом направлении Азербайджанская Республика проделала огромный путь. Соответственно целям развития тысячелетия были разработаны $и$ осуществлены разные программы и проекты, которые форсировали экономический рост страны. Как показывают показатели выше, программы и проекты которые были реализованы в рамках целей развития тысячелетия, дали ощутимые результаты в направлении выполнения важных задач национальной экономической системы. 


\section{Литература:}

Azərbaycan Respublikasının Dövlət Statistika Komitəsinin portalı www.stat.gov.az

"2003-2005-ci illər üçün Azərbaycan Respublikasında yoxsulluğun azaldılması və iqtisadi inkişaf üzrə Dövlət Proqramı” http://www.e-qanun.az/framework/1954

Алакбаров У.К.(2017). Основы управления устойчивым развитием и экологической цивилизацией. Баку: Aspoliqraf, 192 с.

Розенберг Г.С..(2014) "Энергия, экология и экономика. К 40-летию выхода статьи и 90-летию со дня рождения Говарда Т. Одума. Перевод и комментарии" Самарская Лука: проблемы региональной и глобальной экологии, Т. 23, №. 4, с. 5-60.

Цели развития тысячелетия в Европе и Центральной Азии: достижения, проблемы и дальнейшие шаги. Доклад, ООН, Нью-Йорк и Женева, 2010

Azerbaijan Republic: Poverty Reduction Strategy Paper Progress Report 2004, International Monetary Fund October 2004, IMF Country Report No. 04/322

"Voluntary National Review 2017" of the Republic of Azerbaijan on the first steps in the implementation of the 2030 Agenda for Sustainable Development, Baku, 2017

Progress report on Millennium Development Goals -2000-2014, (2015). Ministry of Economy, Azerbaijan Republic, Baku.

Second Voluntary National Review of the Republic of Azerbaijan on the implementation of "Transforming our world: the 2030 Agenda for Sustainable Development".

https://sustainabledevelopment.un.org/content/documents/23411AZERBAIJAN_VNR_Rep ort.pdf 


\title{
XÜLASə
}

Minilliyin İnkişaf Məqsədləri kontekstində Azərbaycan Respublikasının davamı inkişafının ümumi tendensiyaları

\author{
Ülfət MEHDIYYEV \\ Azərbaycan Respublikası Prezidenti yanında Dövlət İdarəçilik \\ Akademiyası, Bakı, Azərbaycan
}

\begin{abstract}
Elmi məqalədə Minilliyin İnkişaf Məqsədləri kontekstində Azərbaycan Respublikasının həyata keçirdiyi proqram və layihələrin nəticələri təhlil edilir. Öncə, MïM-in mahiyyəti və onun çərçivəsində həyata keçirilən tədbirlər haqqında məlumatlar verilir. Azərbaycan Respublikasının milli iqtisadi sisteminin inkişafını təmin edən addımlar ətrafında təhlillər aparılır. Osaslandırılır ki, Azərbaycan Respublikasında ən müxtəlif istiqamətlərdə həyata keçirilən proqram və layihələr olduqca uğurlu nəticələrin əldə olunmasını şərtləndirmişdir. Müxtəlif sahələr üzrə göstəricilər qrafiqlər üzrə təhlil edilmişdir. Həmçinin, əsaslandırılmışdır ki, əldə olunmuş müsbət nəticələr ölkədə insan potensialının inkişafını təmin edir.
\end{abstract}

Açar sözlər: Azərbaycan Respublikası, Minilliyin İnkişaf Məqsədləri, iqtisadiyyat, davamlı inkişaf, insan potensialı 


\title{
SUMMARY
}

\section{General trends of Sustainable Development of the Republic of Azerbaijan in the context of Millennium Development Goals}

\author{
Ulfat MEHDIYYEV \\ Academy of the Public Administration \\ under the President of the Republic of Azerbaijan, \\ Baku, Azerbaijan
}

\begin{abstract}
The scientific article analyzes the results of programs and projects implemented by the Republic of Azerbaijan in the context of the Millennium Development Goals. First of all, it provides information on the essence of the MDGs and the activities undertaken within it. Analyzes are being carried out to ensure the development of the national economic system of the Republic of Azerbaijan. It is justified that the programs and projects implemented in different directions in the Republic of Azerbaijan have led to very successful results. Indicators for different areas were analyzed by charts. It is also reasoned that the positive results achieved will contribute to the development of human potential in the country.
\end{abstract}

Keywords: Azerbaijan Republic, Millenium Development Goals, economics, sustainable development, human potential 